\title{
Purification and Characterization of Adult Oligodendrocyte Precursor Cells from the Rat Optic Nerve
}

\author{
Jingyi Shi, Adrian Marinovich, and Ben A. Barres \\ Stanford University School of Medicine, Department of Neurobiology, Stanford, California 94305-5125
}

\begin{abstract}
Oligodendrocyte precursor cells (OPCs) persist in substantial numbers in the adult brain in a quiescent state suggesting that they may provide a source of new oligodendrocytes after injury. To determine whether adult OPCs have the capacity to divide rapidly, we have developed a method to highly purify OPCs from adult optic nerve and have directly compared their properties with their perinatal counterparts. When cultured in platelet-derived growth factor (PDGF), an astrocyte-derived mitogen, perinatal OPCs divided approximately once per day, whereas adult OPCs divided only once every 3 or $4 \mathrm{~d}$. The proliferation rate of adult OPCs was not increased by addition of fibroblast growth factor (FGF) or of the neuregulin glial growth factor 2 (GGF2), two mitogens that are normally produced by retinal ganglion cells. cAMP elevation has been shown previously to be essential for Schwann cells to survive
\end{abstract}

The CNS has the ability to generate at least some new myelin after injury (Prineas and Connell, 1979; Ludwin, 1981; Prineas et al., 1989, 1993; Blakemore et al., 1996; Gensert and Goldman, 1997; Raine, 1997), but it is not known whether the newly generated myelin is produced by newly formed oligodendrocytes or by oligodendrocytes that escaped injury. Oligodendrocytes, which are terminally differentiated and do not normally divide, are unlikely to provide a significant source of new oligodendrocytes. Oligodendrocyte precursor cells (OPCs), in contrast, persist in the adult brain in appreciable numbers and thus provide a potential source of new oligodendrocytes (ffrench-Constant and Raff, 1986; Wolswijk and Noble, 1989; Wolswijk et al., 1990; Noble et al., 1992). These adult OPCs are relatively quiescent, as are satellite cells in uninjured adult skeletal muscle, which rapidly divide after injury to generate new muscle cells (Allen and Rankin, 1990). In this paper we address whether adult OPCs are capable of dividing rapidly or, alternatively, are just senescent cells with limited ability to help repair a damaged CNS.

We have focused on the rat optic nerve, which is a typical CNS white matter tract that contains primarily astrocytes, oligodendrocytes, and axons of retinal ganglion cells. During development, oligodendrocytes in the optic nerve are generated from rapidly dividing precursor cells (Raff et al., 1983a). Because in serum-free cultures these precursor cells differentiate into oligodendrocytes,

Received Jan. 16, 1998; revised March 30, 1998; accepted April 1, 1998.

This work was supported by National Institutes of Health National Research Service Award 1F32NS101112 (J.S.) and by the National Eye Institute Grant RO1 EY11310 (B.A.B.). We thank Cambridge Neuroscience Inc. for recombinant human GGF2 and Martin Raff for helpful comments on this manuscript.

Correspondence should be addressed to Dr. Ben Barres, Stanford University School of Medicine, Department of Neurobiology, Fairchild Science Building D235, 299 Campus Drive, Stanford, CA 94305-5125.

Copyright (C) 1998 Society for Neuroscience $\quad 0270-6474 / 98 / 184627-10 \$ 05.00 / 0$ and divide in response to GGF2 and other mitogens. Similarly we found that when cAMP levels were elevated, GGF2 alone was sufficient to induce perinatal OPCs to divide slowly, approximately once every $4 \mathrm{~d}$, but adult OPCs still did not divide. When PDGF was combined with GGF2 and cAMP elevation, however, the adult OPCs began to divide rapidly. These findings indicate that adult OPCs are intrinsically different than perinatal OPCs. They are not senescent cells, however, because they retain the capacity to divide rapidly. Thus, after demyelinating injuries, enhanced axonal release of GGF2 or a related neuregulin might collaborate with astrocyte-derived PDGF to induce rapid division of adult OPCs.

Key words: remyelination; demyelination; neuregulin; GGF; PDGF; multiple sclerosis; cAMP whereas in serum-containing cultures they differentiate into type-2 astrocytes (Raff et al., 1983a,b), these cells were initially termed oligodendrocyte-type-2-astrocyte precursor cells (O-2As). Type-2 astrocytes are not generated in the optic nerve (Skoff, 1990; Fulton et al., 1992), however, and thus we now refer to these cells as OPCs (Barres et al., 1992). In the rat optic nerve, new oligodendrocytes are generated from rapidly dividing OPCs from postnatal day 1 (P1) to P45 (Skoff, 1990; Barres et al., 1992). After P45, OPCs persist in the adult optic nerve but divide only rarely (ffrenchConstant and Raff, 1986; Wolswijk and Noble, 1989).

Studies of optic nerve cultures have demonstrated that in contrast to perinatal OPCs, adult OPCs migrate, divide, and differentiate several times more slowly, express vimentin, and have a distinct unipolar rather than a bipolar morphology (ffrench-Constant and Raff, 1986; Wolswijk and Noble, 1989, 1992; Wolswijk et al., 1990; Noble et al., 1992). In addition, some evidence suggests that adult OPCs might be able to divide asymmetrically, unlike perinatal OPCs (Wren et al., 1992). Thus, when studied in mixed optic nerve cultures, adult and perinatal OPCs behave differently.

These studies raise the question of how adult OPCs are related to their perinatal counterparts. They could be intrinsically identical cells that are induced to be quiescent by extracellular signals present in the adult but not in the perinatal nerve. Alternatively, they could represent an intrinsically different cell type. To distinguish between these possibilities, we have developed a method to purify adult OPCs and have directly compared their intrinsic properties with those of purified perinatal OPCs cultured under identical serum-free conditions. We show that purified adult OPCs divide and differentiate several times more slowly than do perinatal OPCs, indicating that their different properties are the result of intrinsic differences. However, providing that their in- 
tracellular levels of cAMP are elevated, we can induce the adult OPCs to divide nearly as rapidly as the perinatal OPCs by a combination of two mitogens, platelet-derived growth factor (PDGF) and glial growth factor (GGF). These results demonstrate that adult OPCs are not senescent cells but, under the right circumstances, have the capacity to rapidly generate new oligodendrocytes.

\section{MATERIALS AND METHODS}

Detailed step-by-step protocols for all procedures are available on request (barres@leland.stanford.edu).

Reagents. Recombinant human trophic factors were obtained from Cambridge Neuroscience (GGF2), Regeneron (BDNF, CNTF), and Peprotech [Rocky Hill, NJ; PDGF-AA, bFGF, neurotrophin-3 (NT-3)]. Monoclonal antibodies were obtained from American Type Culture Collection [Rockville, MD; rat neural antigen 2 (RAN-2), A2B5], Barbara Ranscht [galactocerebroside (GC)], Ilse Somner (O4, O1), Developmental Hybridoma Bank (nestin RAT-401), Boehringer-Mannheim (Indianapolis, IN; MBP) and Ursala Drager (vimentin R5). Polyclonal antibodies were obtained from Dako (Carpinteria, CA; GFAP), Joel Levine (NG-2), and W. Stoffel [proteolipid protein (PLP)].

Purification and culture of perinatal oligodendrocyte precursor cell cultures. OPCs were purified from postnatal rat optic nerves to $>99.9 \%$ purity by sequential immunopanning as described previously (Barres et al., 1992, 1993). Briefly, optic nerves were obtained by dissection from P8 albino rats (Simonsen), and an optic nerve cell suspension was prepared enzymatically with papain. In some experiments, the perinatal OPCs were prepared using trypsin and collagenase as described below for the adult OPCs (except that their concentrations were divided by two because of the younger age of the tissue); their behavior was found to be identical regardless of the enzymes used. The cells were passed sequentially over a series of Petri dishes coated with the following monoclonal antibodies: anti-RAN-2 antibody (IgG) (Bartlett et al., 1981) to deplete astrocytes and meningeal cells, anti-GC antibody (IgG3) (Ranscht et al., 1982) to remove oligodendrocytes including newly formed oligodendrocytes, and A2B5 (IgM) (Eisenbarth et al., 1979) to select the oligodendrocyte precursor cells. The purified OPCs were removed from the A2B5 dish with trypsin and then plated on poly-D-lysine (PDL)-coated tissue culture dishes or glass coverslips. For immunostaining, $\sim 7500$ cells per well were plated in 24 well dishes containing $12 \mathrm{~mm}$ glass coverslips. Clonal culture methods are described in a separate section. The serumfree culture was a modified Bottenstein-Sato medium (Bottenstein and Sato, 1979), containing DMEM (Gibco) with sodium pyruvate (Gibco; 1 $\mathrm{mm}$ ), insulin (Sigma, St. Louis, MO; $5 \mu \mathrm{g} / \mathrm{ml}$ ), transferrin (Sigma; 100 $\mu \mathrm{g} / \mathrm{ml}$ ), bovine serum albumin (Sigma; $100 \mu \mathrm{g} / \mathrm{ml}$ ), progesterone (Sigma; $60 \mathrm{ng} / \mathrm{ml}$ ), putrescine (Sigma; $16 \mu \mathrm{g} / \mathrm{ml}$ ), sodium selenite (Sigma; 40 $\mathrm{ng} / \mathrm{ml}$ ), $N$-acetyl-L-cysteine (NAC; Sigma; $63 \mu \mathrm{g} / \mathrm{ml}$ ) (Mayer and Noble, 1994; Barres et al., 1996), and the appropriate trophic factors. Thyroid hormone (T3) $(30 \mathrm{ng} / \mathrm{ml})$ was not added to the culture medium except when indicated. Cells were fed every $4 \mathrm{~d}$ by doubling the medium at the first feeding and replacing half of the medium at subsequent feedings. All peptide trophic factors were used at plateau concentrations determined by dose-response curves: PDGF (10 ng/ml), CNTF (10 ng/ml), NT-3 (1 $\mathrm{ng} / \mathrm{ml})$, insulin $(5 \mu \mathrm{g} / \mathrm{ml})$, bFGF $(10 \mathrm{ng} / \mathrm{ml})$, and GGF2 (50 ng/ml).

Purification and culture of adult oligodendrocyte precursor cells. OPCs were purified from adult (P60) rat optic nerves to $>95 \%$ purity. Optic nerve cell suspensions were prepared enzymatically with collagenase and trypsin according to the method of Wolswijk and Noble (1989) with minor modifications. Briefly, optic nerves from six to eight adult rats were obtained by dissection and minced into $10-15$ pieces each. The tissue was incubated in calcium and magnesium-free DPBS (DPBS-CMF) containing collagenase at $330 \mathrm{IU} / \mathrm{ml}$ (Sigma) at $37^{\circ} \mathrm{C}$ for $1 \mathrm{hr}$. An equal volume of trypsin at $30,000 \mathrm{IU} / \mathrm{ml}$ (Sigma) in DPBS-CMF was added, and incubation at $37^{\circ} \mathrm{C}$ was continued for $20 \mathrm{~min}$. The suspension was centrifuged $(5 \mathrm{~min} ; 500 \mathrm{~g}$ ), and the cells were incubated in a solution of trypsin at $15,000 \mathrm{IU} / \mathrm{ml}$ and $0.27 \mathrm{~mm}$-EDTA in DPBS-CMF. After 20 min at $37^{\circ} \mathrm{C}$, an equal volume of $20 \%$ heat-inactivated fetal calf serum (FCS; Gibco) containing $0.008 \%$ DNase (Sigma) was added and incubated for $10 \mathrm{~min}$. The tissue was briefly centrifuged, and the supernatant was decanted. A solution containing trypsin inhibitor prepared from ovomucoid (Boehringer-Mannheim; 1.5\%) and bovine serum albumin (BSA; Sigma; $1.5 \%$ ) was added. A cell suspension was prepared by triturating the nerve pieces in the ovomucoid solution sequentially with a $1 \mathrm{ml}$ pipette, a 21-gauge needle, and a 23-gauge needle. The cells were centrifuged, resuspended in $6 \mathrm{ml}$ of another ovomucoid solution $(10 \%$ ovomucoid and 10\% BSA), and washed again. The pellet was then resuspended in $10 \mathrm{ml}$ of DPBS containing $0.02 \%$ BSA and transferred to the first panning dish. The panning procedure was slightly modified from the procedure for purification of perinatal OPCs (Barres et al., 1992, see their text) as follows. The cells were incubated on the anti-RAN-2 antibody-coated dish for $30 \mathrm{~min}$ to deplete type- 1 astrocytes and meningeal cells and then transferred to an A2B5-coated dish for 45 min to select OPC cells. The purified OPCs on the dish were removed with trypsin (Gibco) and cultured identically to the perinatal OPCs (see above).

Clonal culture and analysis. Clonal cultures were prepared by plating $\sim 1200$ purified perinatal OPCs or 3000 adult OPCs in a $60 \mathrm{~mm}$ PDLcoated tissue culture dish (Falcon) containing $2.5 \mathrm{ml}$ of serum-free medium and the indicated trophic factors. Typically, $\sim 50$ OPCs descended through the air-fluid interface to adhere to the bottom of the culture dish. After 4, 8, or $12 \mathrm{~d}$, the clones were scored as described previously (Barres et al., 1994a). In the presence of T3, clones nearly always consisted of cells that were predominantly OPCs or oligodendrocytes, based on their characteristic morphologies (Raff et al., 1983a,b). In the absence of T3, the majority of clones were composed of OPCs, as described previously (Barres et al., 1994a, b; this manuscript). Each clone was scored for its predominant cell type, comprising $>50 \%$ of cells, and for the number of cells it contained. In all cases, the use of survival-promoting peptides and $N$-acetyl-L-cysteine ensured that the percentage of cells surviving in each clone was $>90 \%$. For each condition, 50-100 clones were scored and tabulated. All division rates calculated from these data represent mean \pm SEM. All experiments were repeated at least three times.

5-Bromo-2'-deoxyuridine incorporation and immunofluorescence staining. To label cells in $\mathrm{S}$ phase in vitro, 5-bromo-2'-deoxyuridine (BrdU; Boehringer Mannheim; $10 \mu \mathrm{M}$ ), which is incorporated into replicating DNA, was added to the cultures for 1-24 hr before staining, as indicated. After fixation with $4 \%$ paraformaldehyde for $5 \mathrm{~min}$ at room temperature and a $30 \mathrm{~min}$ incubation in $50 \%$ goat serum to block nonspecific binding, the cell surfaces were stained either with the monoclonal A2B5 antibody (Ascites; 1:200) followed by a fluorescein-coupled goat anti-mouse IgM (Jackson ImmunoResearch, West Grove, PA; mu-chain specific) or with a rabbit anti-NG-2 polyclonal antiserum (1:500; kindly provided by Dr. Joel Levine) followed by a fluorescein-coupled goat anti-rabbit IgG (Jackson ImmunoResearch). The cells were post-fixed in ice-cold ethanol $(70 \%)$ for $10 \mathrm{~min}$, incubated in $2 \mathrm{~N} \mathrm{HCl}$ for $10 \mathrm{~min}$ to denature the nuclear DNA, and then incubated in $0.1 \mathrm{M}$ sodium borate $\left(\mathrm{Na}_{2} \mathrm{~B}_{4} \mathrm{O}_{7}\right)$ for $5 \mathrm{~min}$. The cells were incubated in a solution containing $50 \%$ goat serum and $0.4 \%$ Triton $\mathrm{X}-100$ for $30 \mathrm{~min}$ and incubated with a mouse monoclonal anti-BrdU antibody (Boehringer Mannheim) for $1 \mathrm{hr}$, followed by a Texas Red-conjugated goat anti-mouse IgG. The stained cells were mounted with Citifluor (Chemistry Lab, University of Kent, UK) on glass slides and sealed with nail varnish. A Nikon Microphot-FXA microscope was used to observe the fluorescence staining.

To label cells in S phase in vivo, BrdU $(0.1 \mathrm{mg} / \mathrm{gm}$ of body weight in a DPBS solution) was injected intraperitoneally into the rats $90 \mathrm{~min}$ before death. In some experiments, uptake into OPCs was examined by culturing the purified OPCs for $1 \mathrm{hr}$ and then fixing and staining as described above. In other experiments, uptake was examined by preparing optic nerve sections; in these experiments, the rats were anesthetized with ether and perfused with $4 \%$ paraformaldehyde. The optic nerves were dissected out, further fixed in $4 \%$ paraformaldehyde for $1 \mathrm{hr}$, and then transferred into $30 \%$ sucrose in PBS until equilibrated. The nerves were frozen with OCT compound (Miles, Elkhart, IN) and cut into 8 - $\mu \mathrm{m}$-thick longitudinal sections with a cryostat. The sections were collected onto gelatinized glass slides and stained. The staining procedure was performed as described above except that all of the incubation times were doubled. All BrdU incorporation experiments were repeated at least twice.

Preparation of activated macrophage cultures. Peritoneal macrophages were activated by injecting $0.5 \mathrm{ml}$ of $0.5 \%$ Na-thioglycolate in PBS intraperitoneally into 6-week-old mice. After $24 \mathrm{hr}$, the activated macrophages were collected by injecting $5 \mathrm{ml}$ of PBS intraperitoneally into the thioglycolate-primed mice. The mouse's abdomen was massaged for $15 \mathrm{sec}$ before the peritoneal fluid was removed. The fluid was spun at 400 $g$ for $10 \mathrm{~min}$ and resuspended in DMEM containing $10 \%$ FCS. To condition the culture medium, we plated the macrophages at 50,000 cells per well in a 24 well dish. 


\section{RESULTS}

\section{Evaluation of purity and yield of adult oligodendrocyte precursor cells}

We used immunopanning to obtain highly purified OPCs from optic nerve cell suspensions (see Materials and Methods; Barres et al., 1992). Whereas perinatal OPCs are purified by sequentially panning optic nerve cells on Petri dishes coated with a monoclonal antibody directed against RAN-2 (Bartlett et al., 1981) (to deplete astrocytes and pial cells as well as microglia that adhere to any antibody-coated panning dish via their Fc receptors), a monoclonal anti-GC antibody (Ranscht et al., 1982) (to deplete oligodendrocytes, including newly formed oligodendrocytes that still express OPC markers), and a monoclonal anti-ganglioside A2B5 antibody (Eisenbarth et al., 1979) (to select OPCs), we found that this procedure needed to be modified to purify adult OPCs. In particular, it was essential to omit the anti-GC antibodycoated panning dish because all of the adult OPCs adhered to this dish (see below). Fortunately because newly formed, and thus still A2B5-positive, oligodendrocytes are not present in the adult optic nerve, this dish was not necessary. Using this modified procedure, we typically obtained 1250 cells per adult optic nerve. Given that an adult rat optic nerve contains $\sim 8000$ OPCs (Fulton et al., 1992 ) and that $\sim 15 \%$ of cells survive the enzymatic dissociation, we would expect to obtain $\sim 1200$ adult OPCs per optic nerve, which is quite near the value we obtained. Thus, this procedure isolated nearly all of the surviving OPCs.

To confirm that the isolated cells are in fact adult OPCs, we immunostained the acutely isolated cells with a variety of antibodies and directly compared their antigenic phenotype with the phenotype of acutely isolated perinatal OPCs. Neither the perinatal nor adult OPCs were labeled by antibodies against the astrocyte-specific proteins GFAP, vimentin, and nestin. They also were not labeled by antibodies against the oligodendrocytespecific proteins 2', 3' cyclic nucleotide phosphodiesterase (RIP) (Friedman et al., 1989) (B. Friedman, personal communication) and myelin basic protein (MBP). Greater than $95 \%$ of the putative adult OPC cells, however, stained with antibodies directed against the OPC-specific NG-2 chondroitin sulfate proteoglycan (Levine and Card, 1987; Stallcup and Beasley, 1987). As expected, the perinatal OPCs were not labeled by antigalactocerebroside monoclonal antibodies [either with the $\mathrm{O} 1$ anti-GC antibody (Sommer and Schachner, 1981, 1982) or with the Rmab anti-GC antibody (Ranscht et al., 1982)], but nearly all of the putative adult OPCs brightly labeled with these antibodies, explaining why they adhered to anti-GC antibody-coated dishes.

The presence of GC immunoreactivity on the purified adult cells suggested that they might be immature oligodendrocytes and not OPCs. Therefore we next asked whether the isolated cells, in addition to NG-2 immunoreactivity, had other typical properties of OPCs. First we determined whether they were bipotential, that is, able to differentiate into oligodendrocytes in the absence of serum and into type- 2 astrocytes in the presence of serum. When cultured for $4 \mathrm{~d}$ in serum-free medium containing the survival factors insulin and CNTF but lacking mitogens, $>95 \%$ of the purified adult cells retained GC positivity and developed the typical, highly process-bearing morphology of oligodendrocytes (Fig. 1A). Moreover, over $8 \mathrm{~d}$ of culture, $95 \%$ of the cells developed bright immunoreactivity for the oligodendrocyte-specific proteins MBP (see below) and PLP. When cultured in medium containing $10 \% \mathrm{FCS}$, in contrast, $>95 \%$ of the purified adult cells developed bright immunoreactivity for glial fibrillary acidic pro-
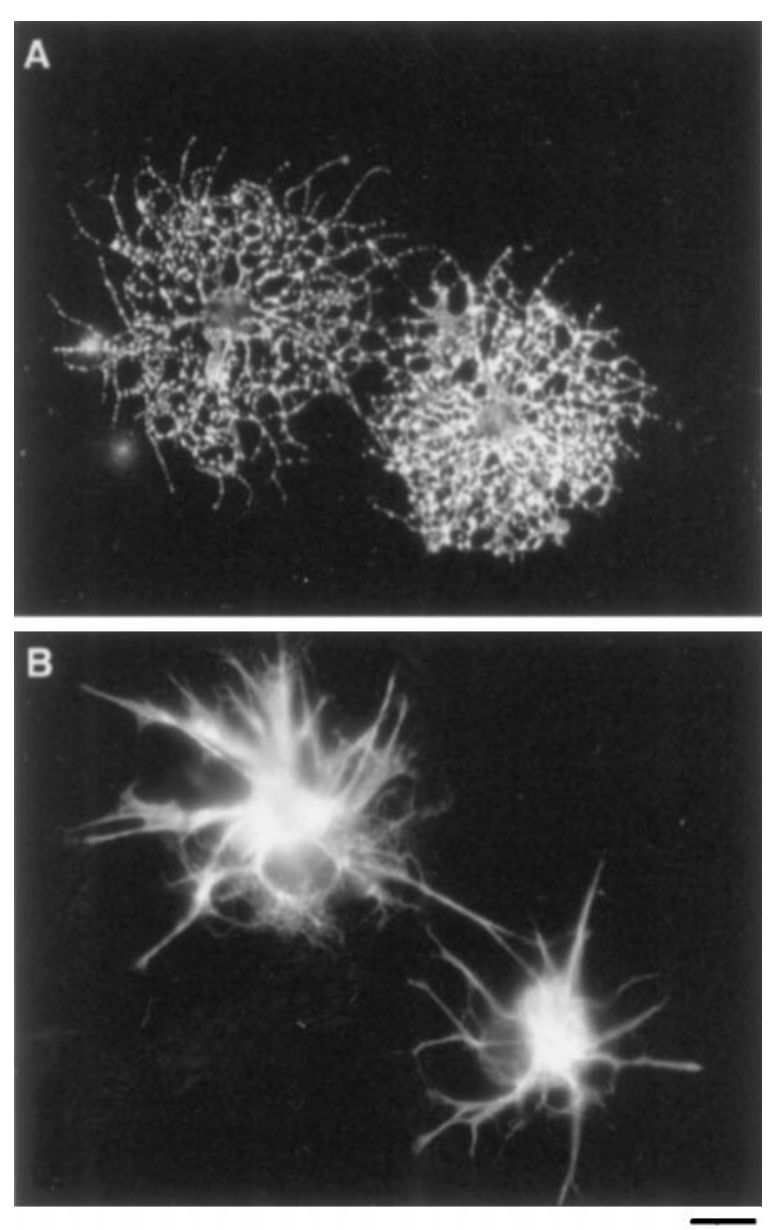

Figure 1. The differentiation of adult OPC cells. $A, B$, Immunofluorescence micrographs of purified adult OPCs that were labeled after $4 \mathrm{~d}$ of culture with a monoclonal anti-GC antibody $(A)$ or a polyclonal GFAP antiserum $(B)$. When cultured in serum-free medium containing insulin and $\operatorname{CNTF}(A)$, nearly all cells differentiated into $\mathrm{GC}^{+}$oligodendrocytes. When cultured in medium containing $10 \%$ fetal calf serum $(B)$, nearly all cells differentiated into GFAP $^{+}$type- 2 astrocytes. Scale bar, $50 \mu \mathrm{m}$.

tein (GFAP) and the typical stellate morphology of type-2 astrocytes (Fig. $1 B$ ). Thus the purified cells had the ability to generate both oligodendrocytes and type- 2 astrocytes.

To determine whether the purified cells retained the ability to divide, as would be expected of precursor cells, we cultured the adult OPCs at clonal density in serum-free medium containing high concentrations of the mitogens and survival factors PDGF, NT-3, CNTF, and insulin. During an $8 \mathrm{~d}$ culture period, $>85 \%$ of the cells divided (see below). Figure 2 shows a typical clone of adult OPCs that was generated by a single purified adult cell cultured for $21 \mathrm{~d}$. Under these conditions, nearly all of the adult OPCs exhibited the typical bipolar morphology of perinatal OPCs, retained bright A2B5 immunoreactivity, and, interestingly, lost their GC immunoreactivity. Together, these findings show that the population of $\mathrm{A} 2 \mathrm{~B} 5^{+}$cells purified from adult optic nerve, despite their initial GC immunoreactivity, have an otherwise similar antigenic phenotype to perinatal OPCs, retain the ability to divide in response to mitogens and to differentiate into oligodendrocytes in serum-free medium and into type- 2 astrocytes in serum-containing medium, and thus are OPCs. 


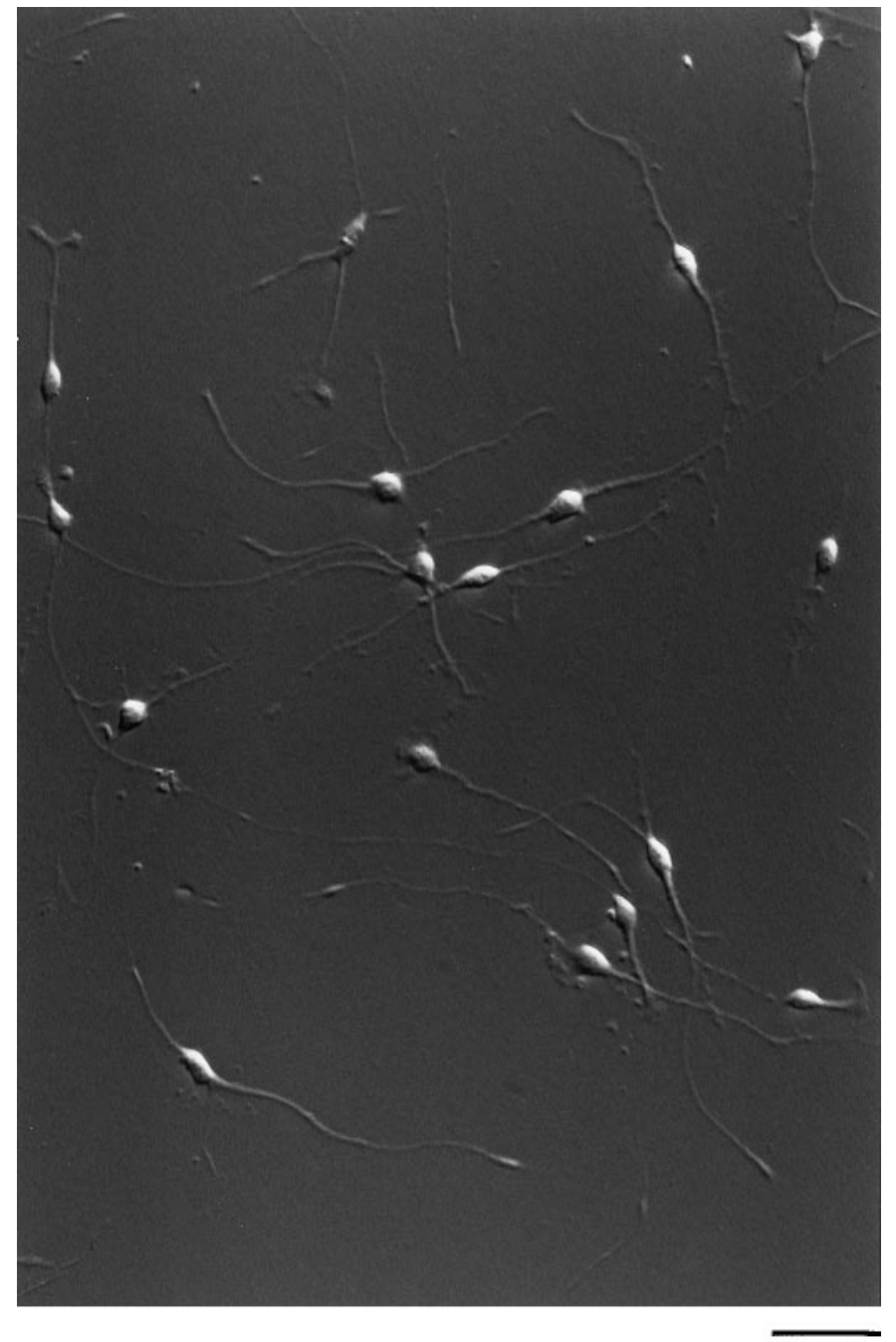

Figure 2. Hoffman micrograph of an adult OPC clone. Purified cells were plated at clonal density and cultured for $21 \mathrm{~d}$ in serum-free medium containing PDGF, NT-3, CNTF, and insulin. Adult OPCs have a bipolar morphology that is indistinguishable from perinatal OPCs. Scale bar, $100 \mu \mathrm{m}$.

\section{Rate of division of purified adult oligodendrocyte precursor cells in vitro}

In mixed optic nerve cultures containing PDGF, adult OPCs divide approximately three to four times more slowly than do perinatal OPCs, but it is not known whether this is the result of cell intrinsic or extrinsic differences. To examine whether there was a cell intrinsic difference, we directly compared the rate of division of purified P8 perinatal and P60 adult OPCs cultured for $8 \mathrm{~d}$ at clonal density in serum-free medium containing PDGF and insulin (see Materials and Methods). The average number of cells per perinatal OPC clone was significantly larger than that for the adult OPC clones (Fig. 3). This size difference cannot be attributed to survival; although not surprisingly a higher percentage of adult than perinatal OPCs did not survive the initial isolation procedure (initial viabilities after $12 \mathrm{hr}$ of culture were typically $\sim 30 \%$ for adult OPCs and $85 \%$ for perinatal OPCs), the adult OPCs that survived the purification procedure exhibited comparable high rates of subsequent survival in culture medium containing PDGF and insulin $(<10 \%$ dead cells on average within each clone over $8 \mathrm{~d}$ of culture for both the perinatal and adult
OPCs). Thus, the difference in clone size reflects a difference in proliferation rate.

As shown in Figure 3, $A$ and $B$, over the first $4 \mathrm{~d}$ of culture most of the perinatal OPCs divided approximately three or four times ( $0.83 \pm 0.02$ divisions per day), whereas most of the adult OPCs did not divide or divided once $(0.1 \pm 0.02$ divisions per day). Over $8 \mathrm{~d}$ of culture (Fig. $3 C, D$ ), most of the perinatal OPCs divided approximately five to six times $(0.63 \pm 0.02$ divisions per day), whereas the adult OPCs divided only approximately twice ( $0.24 \pm 0.2$ divisions per day). The values for division rate of the adult OPCs after $4 \mathrm{~d}$ of culture are only approximate because their average cell cycle time was initially longer than $4 \mathrm{~d}$. Nonetheless, the adult OPCs initially divided many times more slowly than did the perinatal OPCs, and even though over time they tended to divide somewhat more quickly, they remained significantly slower than the perinatal OPCs over culture periods as long as a month.

\section{Comparison of the rates of proliferation of perinatal and adult OPCs in vitro and in vivo}

Because adult OPCs are reported to divide only rarely in vivo, we were surprised by their relatively high rate of division in vitro; therefore, we directly compared their in vitro and in vivo DNA synthesis rates. First, we cultured purified adult and perinatal OPCs in serum-free medium containing PDGF, NT-3, CNTF, and insulin for $4 \mathrm{~d}$. We then added BrdU $(10 \mu \mathrm{M})$ to the culture medium for $90 \mathrm{~min}$ and determined the percentage of cells that incorporated BrdU into their DNA (see Materials and Methods). As shown in Figure $4 A$, only approximately half as many adult OPCs took up BrdU over this time period as did perinatal OPCs, even though we had also included the comitogens NT-3 and CNTF in the culture medium (which were not used in the experiment shown in Fig. 3).

To compare the rate of DNA synthesis of these cells in vivo with their culture rates, we injected BrdU into perinatal (P8) and adult (P60) animals and after the same interval of 90 min killed the animals, purified perinatal and adult OPCs from their optic nerves, and once again determined the percentage of OPCs that had incorporated BrdU. Whereas the percentage of perinatal OPCs that incorporated BrdU was similar in vitro and in vivo, the percentage of adult OPCs that incorporated BrdU in vivo was $\sim 60$ times lower than that in vitro (Fig. $4 B$ ). The adult OPCs in vivo did take up BrdU occasionally, however, as reported previously (ffrench-Constant and Raff, 1986). We confirmed these results by double immunostaining cryosections of the optic nerves from the BrdU-injected animals with the OPC-specific marker, anti-NG-2 antibodies, and anti-BrdU antibodies. Whereas many of the NG-2-positive cells in the perinatal nerves were BrdUpositive, double-labeled cells were only rarely observed in the cryosections of the adult nerves (Fig. 5). The low amount of BrdU incorporation in the adult nerves is not attributable, however, to the inability of BrdU to cross the brain barrier; experiments with tritiated thymidine have yielded identical results (Paterson et al., 1973; see Morshead and van der Kooy, 1992). Therefore, although adult OPCs in vivo divide only rarely, they are capable of dividing more rapidly under the right conditions.

\section{Rate of differentiation of purified adult oligodendrocyte precursor cells in vitro}

In mixed optic nerve cultures, adult OPCs differentiate several times more slowly than do perinatal OPCs (Wolswijk and Noble, 1989). To directly compare the intrinsic rate of differentiation of 


\section{A. P60 OPCs, 4 days in vitro}

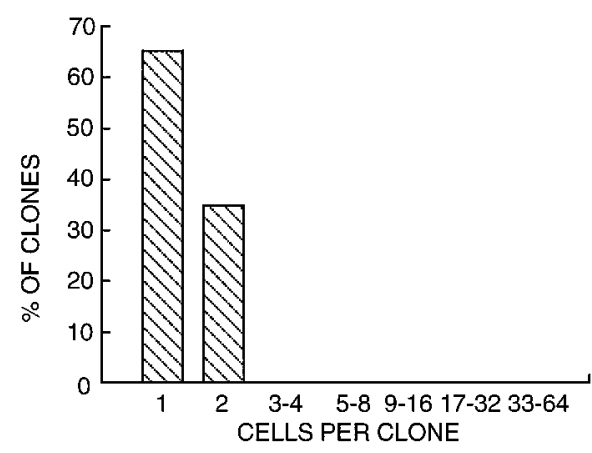

\section{B. P8 OPCs, 4 days in vitro}

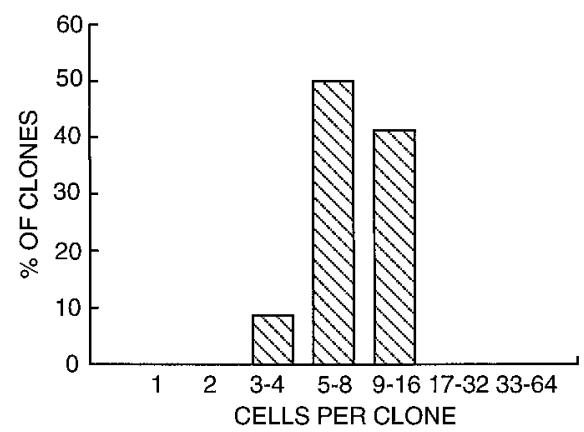

C. P60 OPCs, 8 days in vitro

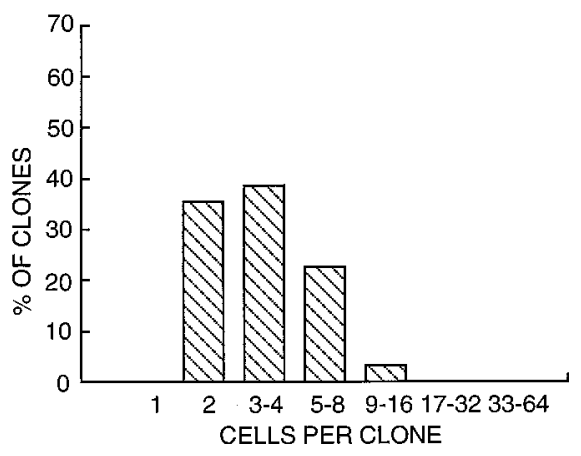

D. P8 OPCs, 8 days in vitro

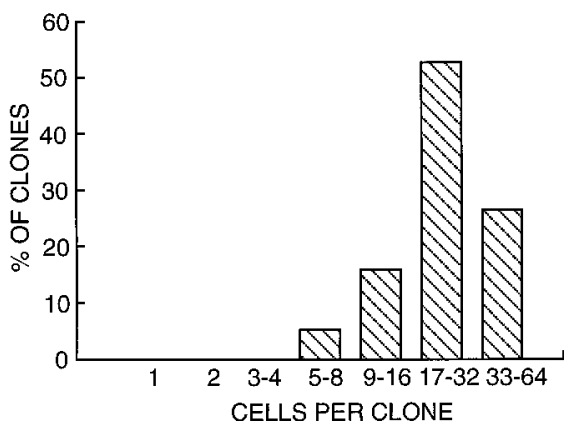

Figure 3. The proliferation rate of adult and perinatal OPCs in culture. Purified adult (P60) $(A, C)$ and perinatal $(\mathrm{P} 8)(B, D)$ OPCs were cultured at clonal density in serum-free medium containing PDGF and insulin. The number of cells per clone was determined after $4 \mathrm{~d}(A, B)$ and $8 \mathrm{~d}(C, D)$ of culture. Under these culture conditions, which lack T3, most of the clones consisted predominantly of OPCs. Note that the average size of adult OPC clones is significantly smaller than is that of the perinatal clones. perinatal and adult OPCs into myelin protein-expressing oligodendrocytes, we cultured the purified P8 and P60 OPCs for varying times before staining them with a monoclonal anti-MBP antibody. As shown in Table 1, the percentage of $\mathrm{MBP}^{+}$cells increased progressively over time for both the P8 and P60 cultures. However, the adult OPCs developed MBP immunoreactivity much more slowly than did the perinatal OPCs. After 4 d, $>80 \%$ of perinatal OPCs had become $\mathrm{MBP}^{+}$, whereas only $\sim 30 \%$ of adult OPCs were positive. By $8 \mathrm{~d}$, however, nearly all of the adult OPCs had differentiated into $\mathrm{MBP}^{+}$oligodendrocytes. Thus the intrinsic rate of differentiation of the adult OPCs was several times slower than that of the perinatal OPCs.

\section{Effects of thyroid hormone on adult OPCs in culture}

Perinatal OPCs have an intrinsic clock mechanism that limits the maximum number of times that they can divide before they give rise to a burst of oligodendrocytes (Temple and Raff, 1986). This clock mechanism is regulated at least in part by T3 (Barres et al., 1994a; Ahlgren et al., 1997). The number of times perinatal OPCs can divide varies inversely with T3 concentration (Barres et al., 1994a), and when cultured in the absence of T3, few perinatal OPCs are able to stop dividing in order to differentiate into oligodendrocytes. To determine whether thyroid hormone also regulates the development of adult OPCs, we cultured purified P8 and P60 OPCs at clonal density in serum-free medium containing PDGF, NT-3, CNTF, and insulin in the presence or absence of $\mathrm{T} 3$ and measured the rate of appearance of oligodendrocyte clones. Remarkably, in the presence but not the absence of T3, the number of oligodendrocyte clones increased dramatically over $12 \mathrm{~d}$ of culture (Fig. 6). In the presence of T3, the differentiation of OPCs into oligodendrocytes within a given clone was highly synchronized so that individual clones at any given time contained predominantly oligodendrocytes or pre- dominantly precursor cells, as reported previously for perinatal OPCs. Together, these observations indicate the presence of a T3-dependent clock mechanism similar to that present in perinatal OPCs.

\section{Effects of other mitogens on the proliferation rate of adult oligodendrocyte precursor cells}

To investigate the potential capacity of adult OPCs to rapidly generate new oligodendrocytes after brain injury, we next tested a variety of culture conditions to see whether we could induce purified adult OPCs to divide more rapidly. We first tested bFGF $(10 \mathrm{ng} / \mathrm{ml})$ because that has been reported to stimulate proliferation of perinatal and adult OPCs (Bogler et al., 1990; Wolswijk and Noble, 1992; Barres et al., 1993; Gard and Pfeiffer, 1993). Over an $8 \mathrm{~d}$ culture period, adult OPCs divided once every $3 \mathrm{~d}$ in PDGF, NT-3, CNTF, and insulin together once every $4 \mathrm{~d}$ in bFGF alone or in PDGF together with bFGF, and once every $6 \mathrm{~d}$ when all of these peptides were added together (data not shown). Similarly, we tested other known mitogens including the chemokine GRO (100 ng/ml), TGF- $\alpha(10 \mathrm{ng} / \mathrm{ml})$, and tumor necrosis factor- $\alpha$ and found that they did not stimulate OPC proliferation. They also did not enhance the rate of OPC proliferation when combined with PDGF, NT-3, and CNTF (data not shown). Similarly, conditioned medium from activated macrophages, mixed glial cells (Noble and Murray, 1984), or B104 cells, which secrete an as yet unidentified perinatal OPC mitogen (Hunter and Bottenstein, 1991), did not increase the proliferation rate of the adult OPCs (data not shown).

Neuregulins (NRG) have recently been reported to promote the proliferation of perinatal OPCs (Brockes et al., 1980; Marchionni et al., 1993; Canoll et al., 1996), so we next assessed their effects on the adult OPCs. Heregulin (100 ng/ml), sensory and motor neuron-derived factor $(100 \mathrm{ng} / \mathrm{ml})$ (Ho et al., 1995), and 


\section{A. IN VITRO}

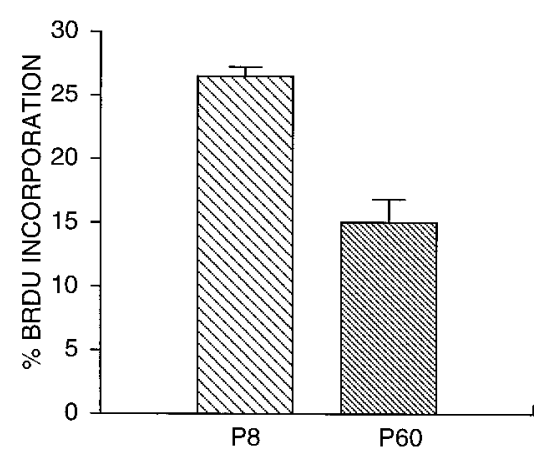

B. IN VIVO

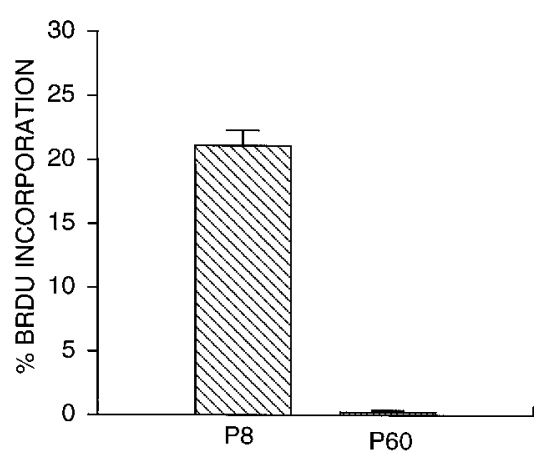

Figure 4. Comparison of the proliferation rate of adult and perinatal $\mathrm{OPCs}$ in vitro and in vivo. $A$, OPCs were cultured in serum-free medium containing PDGF, NT-3, CNTF, and insulin for $4 \mathrm{~d}$ before a 90 min incubation with BrdU $(10 \mu \mathrm{M})$. The percentage of cells that incorporated $\mathrm{BrdU}$ was determined by immunostaining. Values are mean $\pm \operatorname{SEM}(n=3$ coverslips). $B$, BrdU was injected intraperitoneally into adult and P8 rats. After $90 \mathrm{~min}$, OPCs were purified from the optic nerves of the injected rats and cultured for $1 \mathrm{hr}$ before BrdU staining.

GGF2 (100 ng/ml) (Marchionni et al., 1993) did not stimulate proliferation of the adult OPCs in clonal cultures in serum-free medium. The culture medium contained forskolin $(5 \mu \mathrm{M})$, which has been reported to enhance the mitogenic effects of GGF2 and other mitogens on Schwann cells by elevating intracellular cAMP levels (Weinmaster and Lemke, 1990; Minghetti et al., 1996). In cells that have a high basal cAMP-degrading phosphodiesterase activity, however, it is necessary to combine isobutylmethylxanthine (IBMX), an inhibitor of phosphodiesterases, together with forskolin to elevate cAMP levels. When we added GGF2 (50 $\mathrm{ng} / \mathrm{ml})$, forskolin, and $\mathrm{IBMX}(0.1 \mathrm{mM})$ together, perinatal OPCs cultured at clonal density in serum-free medium were stimulated to slowly divide approximately once every $4 \mathrm{~d}$ (Shi et al., 1997), but adult OPCs were not stimulated to divide. However, as shown in Figure $7 A$, when we combined GGF2, IBMX, and forskolin together with PDGF $(10 \mathrm{ng} / \mathrm{ml})$, the adult OPCs began to divide more rapidly, approaching the rate of the perinatal OPCs. This effect was partly attributable to the effects of forskolin and IBMX, which enhanced PDGFstimulated proliferation but were not mitogenic alone (Fig. $7 A$ ), but was also attributable to a further significant enhancement of the proliferation response by GGF2. The nonhydrolyzable, cell membrane-permeant cAMP analog chlorophenylthio-cAMP (CPTcAMP; $125 \mu \mathrm{M}$ ) nearly exactly mimicked the effect of fors-
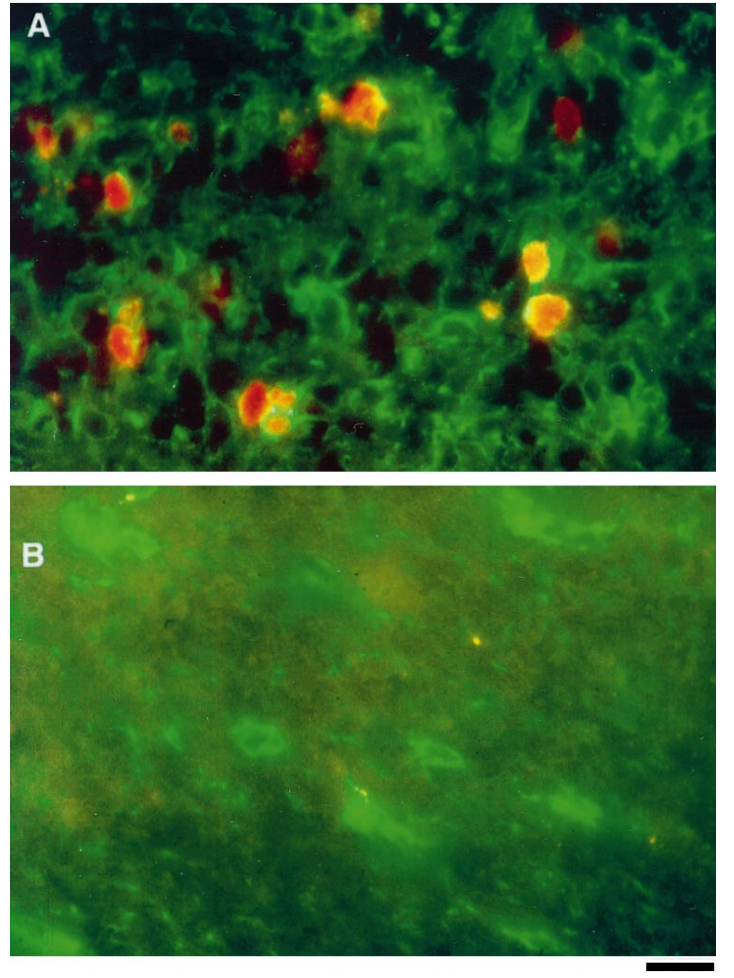

Figure 5. Comparison of the proliferation rate of adult and perinatal OPCs in cryosections. $A, B$, Immunofluorescence micrographs of optic nerve cryosections from $\mathrm{P} 8(A)$ and adult $(B)$ optic nerves. The cryosections were obtained from optic nerves that were fixed $90 \mathrm{~min}$ after an intraperitoneal injection of BrdU and double labeled with NG-2 (green) and BrdU (red) antibodies. Note that in the P8 section, there are many NG-2 ${ }^{+}$cells that are also BrdU ${ }^{+}$. In contrast, in the adult section, none of the $\mathrm{NG}-2^{+}$cells are $\mathrm{BrdU}{ }^{+}$. Scale bar, $50 \mu \mathrm{m}$.

\begin{tabular}{ccc}
\hline \multicolumn{3}{l}{ Table 1. Time course of differentiation of P8 and P60 OPCs } \\
Days in culture & $\% \mathrm{MBP}^{+}(\mathrm{P} 8)$ & $\% \mathrm{MBP}^{+}(\mathrm{P} 60)$ \\
\hline 0 & 0 & 0 \\
1 & $15 \pm 1$ & $11 \pm 1$ \\
2 & $26 \pm 1$ & $22 \pm 1$ \\
3 & $66 \pm 1$ & $25 \pm 1$ \\
4 & $81 \pm 1$ & $31 \pm 1$ \\
8 & $100 \pm 0$ & $95 \pm 3$
\end{tabular}

Approximately 6000 purified OPCs were plated in triplicate onto $12 \mathrm{~mm}$ PDLcoated glass coverslips in 24-well plates. Each well contained $1 \mathrm{ml}$ of serum-free medium containing insulin, but no T3, forskolin, or other peptides. After various times in culture, the slips were stained with a monoclonal anti-MBP-antibody. All values are means \pm SEM.

kolin plus IBMX (data not shown), confirming that the enhancement of NRG responsiveness was caused by elevation of intracellular cAMP levels.

In the presence of PDGF, forskolin and IBMX (or CPTcAMP) also profoundly stimulated the rate at which adult OPCs dropped out of division and gave rise to oligodendrocyte clones, despite the absence of T3, suggesting that high levels of cAMP elevation may regulate the clock mechanism similarly to $\mathrm{T} 3$ (Fig. 7B). GGF2, however, completely antagonized this effect (Fig. 7B). Thus, GGF2 both enhances the proliferation of adult OPCs and inhibits their differentiation into oligodendrocytes. 
A. P60

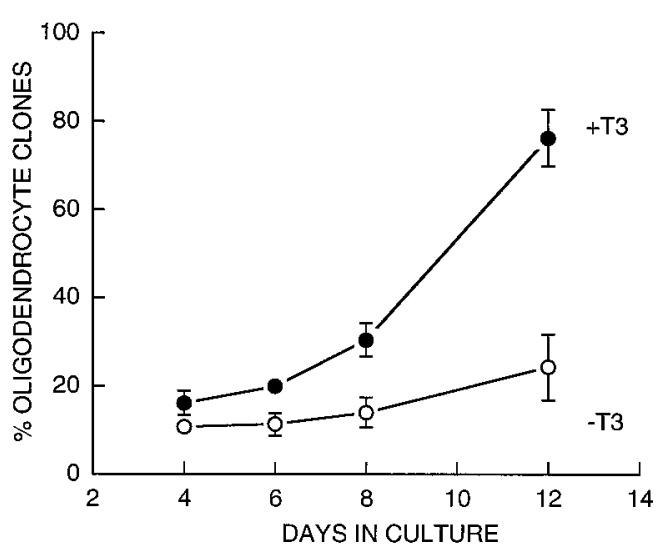

B. P8

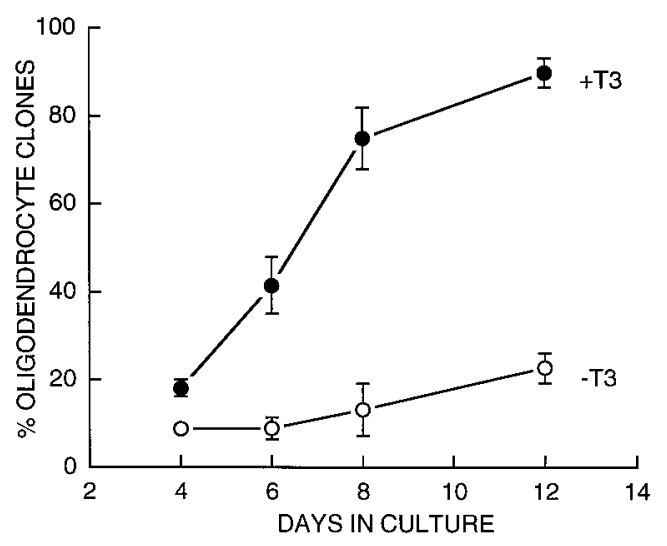

Figure 6. Effects of T3 on the rate of oligodendrocyte generation by OPCs. Purified P60 $(A)$ and P8 $(B)$ OPCs were cultured at clonal density in serum-free medium containing PDGF, NT-3, CNTF, and insulin in the presence (solid circles) and absence (open circles) of T3. The percentages of clones containing predominantly oligodendrocytes ( $>50 \%$ of cells) were counted after $4,6,8$, and $12 \mathrm{~d}$ of culture. All values are mean \pm SEM. T3 strongly enhanced the rate of oligodendrocyte generation from both P60 and P8 OPCs.

\section{DISCUSSION}

\section{Perinatal and adult OPCs are qualitatively similar but quantitatively different}

These results are in good accord with the previous findings of ffrench-Constant and Raff (1986) and Wolswijk and Noble (1989) in that they show that adult OPCs divide and differentiate three or four times more slowly than do perinatal OPCs. Our experiments, however, addressed how this difference arises. By directly comparing the behavior of highly purified perinatal and adult OPCs in the same serum-free tissue culture environment, we found that the main differences between adult and perinatal OPCs can be accounted for by intrinsic and not extrinsic signaling differences. We also found that perinatal and adult OPCs share many fundamental properties, as reported previously. First, they each express the same cell type-specific antigens that distinguish them from astrocytes, oligodendrocytes, and neurons. To our surprise, however, we found that acutely isolated adult OPCs expressed immunoreactivity for galactocerebroside, an oligodendrocyte-specific antigen, whereas perinatal OPCs did not. Nevertheless, their oth-
A.

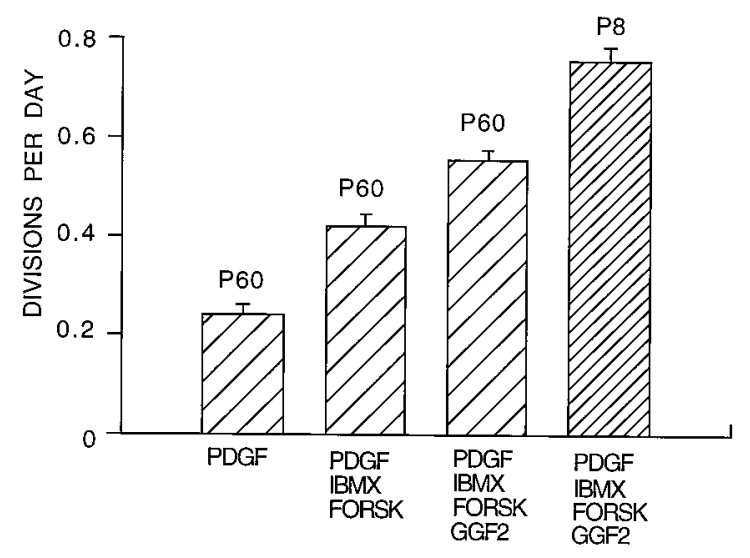

B.

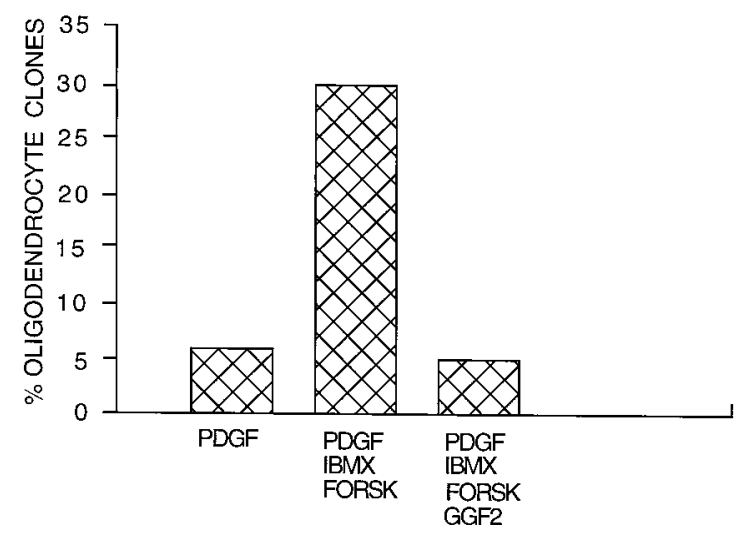

Figure 7. Effects of GGF2 on adult OPCs. Purified P60 and P8 OPCs were cultured for $8 \mathrm{~d}$ at clonal density in serum-free medium containing $P D G F, G G F 2, I B M X(0.1 \mathrm{~mm})$, and forskolin $(5 \mu \mathrm{M})$, as indicated. $A$, The division rate of $\mathrm{P} 8$ and $\mathrm{P} 60$ was calculated from the clone size. $B$, The rate of oligodendrocyte generation by P60 OPCs was determined by the percentage of clones that primarily consisted of oligodendrocytes. GGF2 enhances the rate of proliferation of P60 OPCs and inhibits their differentiation into oligodendrocytes. All values are mean \pm SEM. FORSK, Forskolin; IBMX, isobutylmethylxanthine.

erwise characteristic $\mathrm{OPC}$-antigenic phenotype and their ability to divide and to generate type- 2 astrocytes and oligodendrocytes clearly indicated that these cells are OPCs.

We also found that adult OPCs responded to the same peptides that have been shown previously to stimulate perinatal OPC survival and proliferation, including PDGF, CNTF, NT-3, IGF-1, FGF, and GGF2. Similarly, adult OPCs exhibited an obligate relationship between proliferation and differentiation; proliferating cells did not express oligodendrocyte markers (such as CNPase, MBP, or PLP), and when the mitogens were withdrawn, all of the adult OPCs differentiated into postmitotic oligodendrocytes. Lastly, the adult OPCs also shared with the perinatal OPCs a T3-dependent intrinsic clock mechanism that counts and limits the maximum number of times that they can divide. Thus, adult and perinatal OPCs shared many qualitatively similar properties, but they also exhibited remarkable quantitative differences in their rate of proliferation and differentiation.

There are, however, some differences between our study and previous reports. First, we were unable to observe the presence of vimentin immunoreactivity in the adult OPCs. Second, we did 
not observe a difference in morphology between perinatal and adult OPCs; both cell types were predominantly bipolar in our cultures. We also did not observe any evidence of asymmetric division (Wren et al., 1992); all adult OPC clones grew symmetrically in our cultures as evidenced by an exponential rate of division. Lastly, we were unable to induce "reversion" or rapid proliferation of the adult OPCs using FGF (Wren et al., 1992). Rather, we found that the addition of bFGF made them divide even more slowly. It is possible that these differences can be accounted for by differences in experimental conditions. In particular our experiments used purified preparations of OPCs, whereas previous work has focused on the behavior of adult OPCs in optic nerve cultures.

\section{The differences between perinatal and adult OPCs are cell autonomous}

The large differences in the rates of division and differentiation between perinatal and adult OPCs must be caused by a cell intrinsic difference, because the differences were maintained even after prolonged periods of culture up to 1 month in the same culture environment. Cell intrinsic differences, however, are not sufficient to account for the quiescence of the adult OPCs in vivo. In vitro, nearly all of the adult OPCs could be stimulated by PDGF to divide approximately once every 3 or $4 \mathrm{~d}$, whereas in vivo, adult OPCs divided only rarely. This suggests that in vivo mitogen levels are low [or proliferation inhibitors such as TGF- $\beta$ are present (McKinnon et al., 1993)], raising the interesting question of why adult OPCs that are not dividing do not differentiate within the nerve as they would in vitro. We have recently found that Notch1 receptors are expressed by both perinatal and adult OPCs, that the Notch1 ligand Jagged1 is expressed by oligodendrocytes, and that activation of the Notch pathway prevents OPCs from differentiating into oligodendrocytes (Wang et al., 1998). Thus, as oligodendrocytes accumulate in the nerve, the differentiation of OPCs may be inhibited. In any case, our findings show that adult and perinatal OPCs behave differently both because they are intrinsically different cell types and because the adult and perinatal environments within the nerve are different.

The intrinsically slower rate of division of adult OPCs compared with that of perinatal OPCs suggests the possibility that the adult OPCs are simply senescent cells. In general, the number of times that mitotic cells can divide depends on the lifespan of the organism. For example, cells isolated from human infants have a capacity to divide as many as 80 times (Campisi et al., 1995), whereas cells isolated from rodent pups can divide only $\sim 15$ times (Todaro and Green, 1965). After reaching their maximum number of divisions, senescent cells survive but lose the ability to divide (provided they do not transform). Although it is plausible that many adult OPCs have divided as many as 15 times, it is not known whether the same division limits pertain to precursor cells. Our data indicate that adult OPCs are not senescent cells. First, we have been able to keep many of the adult OPCs dividing for at least another seven divisions over a month of culture. Moreover, unlike senescent cells, the adult OPCs can be signaled to divide nearly as rapidly as the perinatal OPCs when they are treated with a combination of PDGF and GGF2. Thus, adult OPCs retain considerable proliferative capacity.

How are adult OPCs generated? One possibility is that "adult" OPCs are an alternative cell fate generated either by perinatal OPCs (Wolswijk and Noble, 1989) or by an as yet unidentified multipotent precursor cell (ffrench-Constant and Raff, 1986). Alternatively, perinatal OPCs may progressively change over time or with successive divisions, ultimately attaining the properties of adult OPCs. For instance, the cell cycle inhibitory molecule p27 accumulates in perinatal OPCs as they divide, progressively slowing their rate of division (Durand et al., 1997; Tikoo et al., 1997). We tend to favor the "progressive change" model because, in addition to $\mathrm{p} 27$ accumulation, most OPCs purified from P14 optic nerves divide more slowly in culture than do P1 OPCs (Barres et al., 1994a; Gao and Raff, 1997), although only 10\% of P14 OPCs are adult OPCs (Wolswijk and Noble, 1989; Wolswijk et al., 1990). Moreover, proliferating E18 oligodendrocyte precursors cells in culture progressively change their properties to resemble that of the P7 precursors, suggesting that progressive maturation is an intrinsic property of these cells (Gao and Raff, 1997).

\section{PDGF and GGF2 collaborate to promote rapid division of adult OPCs in vitro}

It has been uncertain whether adult OPCs have the capacity to divide rapidly. The most important observation in this study is that adult OPCs have the capacity to divide rapidly. Although PDGF was only able to stimulate proliferation of the adult OPCs at a rate of one division every 3 to $4 \mathrm{~d}$, and GGF2 was insufficient by itself to promote their division at all, when cAMP levels were elevated, adult OPCs stimulated by PDGF and GGF2 together divided nearly as rapidly as perinatal OPCs. In addition, GGF2 strongly inhibited the differentiation of OPCs into oligodendrocytes. CAMP elevation, which is not mitogenic by itself, seems to act by enhancing responsiveness of OPCs to GGF2, just as it has been shown previously to enhance the responsiveness of Schwann cells to their mitogens (Weinmaster and Lemke, 1990). Because forskolin alone was insufficient to enhance responsiveness, it is likely that the adult OPCs in culture express high levels of a cAMP-degrading phosphodiesterase. Although adult OPCs stimulated by PDGF and GGF2 can divide rapidly, our study did not address whether they have fully "reverted" to a perinatal OPC phenotype. In any case, GGF2 helps to stimulate the division of adult OPCs in culture, just as it does that of perinatal OPCs (Canoll et al., 1996).

Does GGF2 help to stimulate OPC division in vivo? PDGF-AA has been shown previously to be secreted by optic nerve astrocytes as well as by retinal ganglion cells [although it does not appear to be targeted to their axons (Mudhar et al., 1993)] and to play a crucial role in stimulating the survival and proliferation of OPCs during normal development; in transgenic mice lacking PDGFAA, few OPCs develop, and in transgenic mice overexpressing PDGF-AA, there are a larger number of OPCs (Calver and Richardson, 1997). It is not known, however, whether GGF or other NRGs are also present in vivo in sufficient amounts to stimulate OPC proliferation. In support of this possibility, retinal ganglion cells normally synthesize several splice forms of NRG, including GGF2, and target them to their axons, and perinatal OPCs express the $\mathrm{NRG}$ receptors erbB2 and erbB3, in addition to being stimulated to divide by GGF2 (Canoll et al., 1996; J. Shi, P. Osheroff, and B. A. Barres, unpublished observations). Moreover, signals from neurons are essential for stimulating the proliferation of developing OPCs; when the optic nerve is transected or when the electrical activity of retinal ganglion cells is silenced by intraocular injection of tetrodotoxin, proliferation of OPCs ceases (Barres and Raff, 1993). Thus, it is likely that GGF2 or a related neuregulin normally collaborates with PDGF in promoting proliferation of OPCs in vivo.

\section{Implications for demyelinating injuries and diseases}

How are adult OPCs generated during normal development? A hypothetical model that would be consistent with our observa- 
tions is as follows. Initially during development, OPCs divide rapidly and generate oligodendrocytes. As they divide, they progressively alter their properties, dividing more and more slowly. As sufficient oligodendrocytes are generated and myelination terminates, the amount of GGF released from axons may diminish as a result of the myelin sheathing of the axons, thus further slowing the rate of OPC proliferation. PDGF produced by adult astrocytes probably drives the residual slow rate of OPC proliferation as well as promoting their survival. Once a sufficient number of oligodendrocytes is generated, the further differentiation of adult OPCs into oligodendrocytes is likely to be prevented by activation of their Notch pathway by Jagged1 on the surfaces of nearby oligodendrocytes (Wang et al., 1998). This would ensure that some OPCs are retained in the adult as a potential reservoir of precursor cells that have the potential to generate new oligodendrocytes in the case of injury, much as satellite cells in adult muscle can generate new muscle fibers after injury. It is also possible that adult OPCs subserve other functions as well.

Injury or diseases of the optic nerve, such as multiple sclerosis, that destroy oligodendrocytes and myelin may thus allow this oligodendrocyte-derived inhibition of OPC proliferation and differentiation to be released. The resulting combination of PDGF from astrocytes and GGF2 from the axons may then synergize to stimulate rapid proliferation of the adult OPCs. Consistent with this model, rapidly proliferating OPC-like cells have been observed in remyelinating rabbit optic nerves (Carroll and Jennings, 1994), and endogenous precursor cells in the white matter of the brain are able to remyelinate axons, although it is unclear yet whether these precursor cells are OPCs (Gensert and Goldman, 1997). It has been controversial whether mature oligodendrocytes can be induced to divide or revert into OPCs (Ludwin, 1984; Wood and Bunge, 1991; Norton, 1996); Canoll et al. (1996) reported that GGF2 stimulation induced cortical oligodendrocytes to revert to OPCs; so far, however, we have been unable to induce optic nerve oligodendrocytes to divide or revert to OPCs. Moreover, the evidence that mature oligodendrocytes derived from the adult nervous system can remyelinate axons derives in part from the use of fractions of cells enriched in $\mathrm{GC}^{+}$cells (Wood and Bunge, 1991); our results suggest that these fractions may have included adult oligodendrocyte precursor cells, which also express GC, as well as oligodendrocytes.

Although the injured brain has at least some capacity to remyelinate, in many cases remyelination ultimately fails or is incomplete (Raine, 1997). Our findings suggest at least two approaches for enhancing remyelination. First, remyelination might fail because levels of OPC mitogens are insufficient to drive their proliferation. For instance, if electrical activity is necessary for optimal production or release of neuronal-derived mitogens such as GGF, the conduction block induced by demyelination may prevent adequate production or release of GGF. Therefore the rate of remyelination from new oligodendrocytes generated by endogenous adult OPCs might be enhanced by delivery of exogenous mitogens including PDGF and GGF into the injured region of the brain.

Second, remyelination might fail if there are insufficient adult OPCs available, either because they have been depleted by injury or their intrinsic clock mechanism or because they are unable to migrate into a lesion. A recent study has demonstrated that adult OPCs are in fact depleted in the vicinity of remyelinated lesions, suggesting a limited ability of these cells to renew themselves (Keirstead et al., 1998). The remarkable ability of purified perinatal OPCs transplanted into demyelinated brain to remyelinate axons has been clearly demonstrated previously (Groves et al.,
1993; Utzschneider et al., 1994; Blakemore et al., 1996; Duncan, 1996; Archer et al., 1997; Franklin and Blakemore, 1997; Scolding, 1997). Unfortunately, however, perinatal OPCs are not a useful source of remyelinating cells because of lack of availability and graft rejection problems. Instead, adult OPCs could be purified from the patient's own white matter, expanded in vitro with PDGF and GGF, and ultimately transplanted into a demyelinated lesion. Human white matter contains cells that closely resemble adult OPCs in the rat optic nerve (Armstrong et al., 1992). Therefore it is likely that these cells could be purified from adult white matter and expanded in vitro using immunopanning and culture procedures similar to those described here. We hope in future experiments to determine the ability of adult OPCs to remyelinate injured white matter after transplantation.

\section{REFERENCES}

Ahlgren SC, Wallace H, Bishop J, Neophytou C, Raff MC (1997) Effects of thyroid hormone on embryonic oligodendrocyte precursor cell development in vivo and in vitro. Mol Cell Neurosci 9:420-432.

Allen RE, Rankin LL (1990) Regulation of satellite cells during skeletal muscle growth and development. Proc Soc Exp Biol Med 194:81-86.

Archer DR, Cuddon PA, Lipsitz D, Duncan I (1997) Myelination of the canine central nervous system by glial cell transplantation: a model for repair of human myelin disease. Nat Med 3:54-59.

Armstrong RC, Dorn HH, Kufta CV, Friedman E, Dubois-Dalcq ME (1992) Preoligodendrocytes from adult human CNS. J Neurosci 12:1538-1547.

Barres BA, Raff MC (1993) Proliferation of oligodendrocyte precursor cells depends on electrical activity in axons. Nature 361:258-260.

Barres BA, Hart IK, Coles HSR, Burne JF, Voyvodic JT, Richardson WD, Raff MC (1992) Cell death and control of cell survival in the oligodendrocyte lineage. Cell 70:31-46.

Barres BA, Schmid R, Sendtner M, Raff MC (1993) Multiple extracellular signals are required for long-term oligodendrocyte survival. Development 118:283-295.

Barres BA, Lazar MA, Raff MC (1994a) A novel role for thyroid hormone, glucocorticoids, and retinoic acid in timing oligodendrocyte development. Development 120:1097-1108.

Barres BA, Raff MC, Gaese F, Bartke I, Dechant G, Barde YA (1994b) A crucial role for neurotrophin-3 in oligodendrocyte development. Nature 367:371-375.

Barres BA, Burne JF, Holtmann B, Thoenen H, Sendtner M, Raff MC (1996) Ciliary neurotrophic factor enhances the rate of oligodendrocyte generation. Mol Cell Neurosci 8:146-156.

Bartlett PF, Noble MD, Pruss RM, Raff MC, Rattray S, Williams CA (1981) Rat neural antigen-2 (RAN-2): a cell surface antigen on astrocytes, ependymal cells, Muller cells and lepto-meninges defined by a monoclonal antibody. Brain Res 204:339-351.

Blakemore WF, Franklin RJ, Noble M (1996) Glial cell transplantation and the repair of demyelinating diseases. In: Glial cell development (Jessen KR, Richardson WD, eds), pp 209-220. Oxford: BIOS Scientific.

Bogler O, Wren D, Barnett S, Land H, Noble M (1990) Cooperation between two growth factors promotes extended self-renewal and inhibits differentiation of oligodendrocyte-type-2 astrocyte (O-2A) progenitor cells. Proc Natl Acad Sci USA 87:6368-6372.

Bottenstein JE, Sato GH (1979) Growth of a rat neuroblastoma cell line in serum-free supplemented medium. Proc Natl Acad Sci USA 76: 514-517.

Brockes JP, Lemke GE, Balzer Jr DR (1980) Purification and preliminary characterization of a glial growth factor from the bovine pituitary. J Biol Chem 255:8374-8377.

Calver AR, Richardson WD (1997) Control of oligodendrocyte number by PDGF AA in transgenic mice. Dev Neurosci 19:131.

Campisi J, Dimri G, Hara E (1995) Control of replicative senescence. Handbook of the biology of aging, 4th Edition.

Canoll PD, Musachhio JM, Hardy R, Reynolds R, Marchionni MA, Salzer JL (1996) GGF/neuregulin is a neuronal signal that promotes the proliferation and survival and inhibits the differentiation of oligodendrocyte progenitors. Neuron 17:229-243.

Carroll W M, Jennings AR (1994) Early recruitment of oligodendrocyte precursors in CNS demyelination. Brain 117:563-578. 
Dubois-Dalcq M, Armstrong R (1990) The cellular and molecular events of CNS remyelination. Bioessays 12:569-576.

Duncan ID (1996) Glial cell transplantation and remyelination of the central nervous system. Neuropathol Appl Neurobiol 22:87-100.

Durand B, Gao FB, Raff MC (1997) Accumulation of the cyclindependent kinase inhibitor $\mathrm{p} 27 / \mathrm{Kip} 1$ and the timing of oligodendrocyte differentiation. EMBO J 16:306-317.

Eisenbarth GS, Walsh FS, Nirenburg M (1979) Monoclonal antibodies to a plasma membrane antigen of neurons. Proc Natl Acad Sci USA 76:4913-4916.

ffrench-Constant C, Raff MC (1986) Proliferating bipotential glial progenitor cells in adult rat optic nerve. Nature 319:499-502.

Franklin RJ, Blakemore WF (1997) Transplanting oligodendrocyte progenitors into the adult CNS. J Anat 190:23-33.

Friedman B, Hockfield S, Black JA, Woodruff KA, Waxman SG (1989) In situ demonstration of mature oligodendrocytes and their processes. Glia 2:380-390.

Fulton BP, Burne JF, Raff MC (1992) Visualization of O-2A progenitor cells in the developing and adult rat optic nerve by quisqualatestimulated cobalt uptake. J Neurosci 12:4816-4833.

Gao F, Raff MC (1997) Cell size control and cell intrinsic maturation program in proliferating oligodendrocyte precussor cells. J Cell Biol 138:1367-1377.

Gard AL, Pfeiffer SE (1993) Glial cell mitogens bFGF and PDGF differentially regulate development of $\mathrm{O} 4+\mathrm{GalC}+$ oligodendrocyte progenitors. Dev Biol 159:618-630.

Gensert JM, Goldman JE (1997) Endogenous progenitors remyelinate demyelinated axons in the adult CNS. Neuron 19:197-203.

Groves AK, Barnett SC, Franklin RJ, Crang AJ, Mayer M, Blakemore WF, Noble M (1993) Repair of demyelinated lesions by transplantation of purified O-2A progenitor cells. Nature 362:453-455.

Ho WH, Armanini MP, Nuijens A, Phillips HS, Osheroff PL (1995) Sensory and motor neuron derived factor: a novel heregulin variant highly expressed in sensory and motor neurons. J Biol Chem 270:14523-14532.

Hunter SF, Bottenstein JE (1991) O-2A glial progenitors from mature brain respond to CNS neuronal cell line-derived growth factors. J Neurosci Res 28:574-582.

Keirstead H, Levine J, Blakemore W (1998) Response of oligodendrocyte progenitor cell population (defined by NG2 labelling) to demyelination of the adult spinal cord. Glia 22:161-170.

Levine JM, Card JP (1987) Light and EM localization of a cell surface antigen (NG-2) in the rat cerebellum. J Neurosci 7:2711-2720.

Ludwin SK (1981) Pathology of demyelination and remyelination. In: Demyelinating disease: basic and clinical electrophysiology (Waxman SG, Ritchie JM, eds), pp 123-168. New York: Raven.

Ludwin SK (1984) Proliferation of mature oligodendrocytes after trauma to the CNS. Nature 308:274-275.

Marchionni MA, Goodearl ADJ, Chen MS, Bermingham-McDonough O, Kirk C, Hendricks M, Danehy F, Misumi D, Suddhalter J, Kobayashi K, Wroblewski D, Lynch C, Baldassare M, Hiles I, Davis JB, Hsuan JJ, Totty NF, Otsu M, McBurney RN, Waterfield MD, Stroobant P, Gwynne D (1993) Glial growth factors are alternatively spliced erbB2 ligands expressed in the nervous system. Nature 362:312-318.

Mayer M, Noble M (1994) $N$-Acetyl-L-cysteine is a pluripotent protector against cell death and enhancer of trophic factor mediated cell survival in vitro. Proc Natl Acad Sci USA 91:7496-7500.

McKinnon RD, Piras G, Ida JA, Dubois-Dalcq M (1993) A role for TGF-B in oligodendrocyte differentiation. J Cell Biol 121:1397-1407.

Minghetti L, Goodearl A, Mistry K, Stroobant P (1996) Glial growth factors are specific mitogens for glial cells. J Neurosci Res 43:684-693.

Morshead CM, van der Kooy D (1992) Postmitotic death is the fate of constitutively proliferating cells in the subependymal layer of the adult mouse brain. J Neurosci 12:249-256.

Mudhar HS, Pollack R, Wang C, Stiles C, Richardson W (1993) PDGF and its receptors in the developing rodent retina and optic nerve. Development 118:539-552.

Noble M, Murray K (1984) Purified astrocytes promote the in vitro divisions of a bipotential glial progenitor cell. EMBO J 3:2243-2247.

Noble M, Wren D, Wolswijk G (1992) The O-2A (adult) progenitor cell: a glial stem cell of the adult central nervous system. Semin Cell Biol $3: 413-422$.

Norton WT (1996) Do oligodendrocytes divide? Neurochem Res 1:495-503.
Paterson JA, Privat A, Ling A, Leblond CP (1973) Investigation of glial cells in semithin sections. III. Transformation of subependymal cells into glial cells, as shown by radioautography after $\left[{ }^{3} \mathrm{H}\right]$ thymidine injection into the lateral ventricle of the brain of young rats. J Comp Neurol 149:83-102.

Prineas JW, Connell F (1979) Remyelination in multiple sclerosis. Ann Neurol 5:22-31.

Prineas JW, Kwon EE, Goldenberg PZ, Ilyas AA, Quarles RH, Benjamins JA, Sprinkle TJ (1989) Multiple sclerosis: oligodendrocyte proliferation and differentiation in fresh lesions. Lab Invest 61:489-503.

Prineas JW, Kwon EE, Sharer LR, Cho ES (1993) Multiple sclerosis: remyelination of nascent lesions. Ann Neurol 33:137-151.

Raff MC, Miller RH, Noble M (1983a) A glial progenitor cell that develops in vitro into an astrocyte or an oligodendrocyte depending on culture medium. Nature 303:390-396.

Raff MC, Abney ER, Cohen J, Lindsay R, Noble M (1983b) Two types of astrocytes in cultures of developing rat white matter: differences in morphology, surface gangliosides, and growth characteristics. J Neurosci 3:1289-1300.

Raine CS (1997) The Norton lecture: a review of the oligodendrocyte in the multiple sclerosis lesion. J Neuroimmunol 77:135-152.

Ranscht B, Clapshaw PA, Price J, Noble M, Seifert W (1982) Development of oligodendrocytes and Schwann cells studied with a monoclonal antibody against galactocerebroside. Proc Natl Acad Sci USA 79:2709-2713.

Scolding N (1997) Strategies for repair and remyelination in demyelinating diseases. Curr Opin Neurobiol 10:193-200.

Shi J, Osheroff P, Barres BA (1997) PDGF and GGF2 collaborate to promote the proliferation of oligodendrocyte precursor cells. Soc Neurosci Abstr 23:662.11.

Skoff RP (1990) Gliogenesis in rat optic nerve: astrocytes are generated in a single wave before oligodendrocytes. Dev Biol 139:149-168.

Sommer I, Schachner M (1981) Monoclonal antibodies (O1 to O4) to oligodendrocyte cell surfaces: an immunocytochemical study in the central nervous system. Dev Biol 83:311-327.

Sommer I, Schachner M (1982) Cells that are O4-antigen positive and O1-negative differentiate into O1-positive oligodendrocytes. Neurosci Lett 29:183-188.

Stallcup WB, Beasley L (1987) Bipotential glial precursor cells of the optic nerve express the NG-2 proteoglycan. J Neurosci 7:2737-2744.

Temple S, Raff MC (1986) Clonal analysis of oligodendrocyte development in culture: evidence for a developmental clock that counts cell divisions. Cell 44:773-779.

Tikoo R, Casaccia-Bonnefil P, Chao MV, Koff A (1997) Changes in cyclin-dependent kinase 2 and p27kip1 accompany glial cell differentiation of central glia-4 cells. J Biol Chem 272:442-447.

Todaro GJ, Green H (1965) Quantitative studies of the growth of mouse embryo cells in culture and their development in established lines. J Cell Biol 17:299-313.

Utzschneider DA, Archer DR, Koscis JD, Waxman SG, Duncan ID (1994) Transplantation of glial cells enhances action potential conduction of amyelinated spinal cord axons in the myelin-deficient rat. Proc Natl Acad Sci USA 91:53-57.

Wang S, Sdrulla AD, diSibia G, Bush G, Nofziger D, Hicks C, Weinmaster G, Barres BA (1998) Notch receptor activation inhibits oligodendrocyte differentiation. Neuron, in press.

Weinmaster G, Lemke G (1990) Cell specific cyclic AMP mediated induction of the PDGF receptor. EMBO J 9:915-920.

Wolswijk G, Noble M (1989) Identification of an adult-specific glial progenitor cell. Development 105:387-400.

Wolswijk G, Noble M (1992) Cooperation between PDGF and FGF converts slowly dividing O-2A adult progenitor cells to rapidly dividing cells with the characteristics of perinatal O-2A progenitor cells. J Cell Biol 118:889-897.

Wolswijk G, Riddle PN, Noble M (1990) Coexistence of perinatal and adult forms of a glial progenitor cell during development of the rat optic nerve. Development 109:691-698.

Wood PM, Bunge RP (1991) The origin of remyelinating cells in the adult central nervous system: the role of the mature oligodendrocyte. Glia 4:225-232.

Wren D, Wolswijk G, Noble M (1992) In vitro analysis of the origin and maintenance of O-2A adult progenitor cells. J Cell Biol 116:167-176. 